Brit. J. Ophthal. (1964) 48, 404.

\title{
CORRESPONDENCE
}

\section{PHOSPHOLINE IODIDE}

\section{To the Editorial Committee of the British Journal of Ophthalmology}

SiRs,-Of a total of twenty squinting children being treated with phospholine iodide 0.125 per cent., I have recently had two very ill with diarrhoea and vomiting. I feel this has been serious enough to prevent one continuing with this line of treatment, and would be grateful for information as to the incidence of the complication in other clinics.

Yours faithfully,

R. A. D. Crawford.

80 Gladstone RoAD,

BROADSTAIRS, KENT.

May 5, 1964.

\section{BOOK REVIEW}

Intra-ocular Lenses and Implants. By Peter ChOyce. 1964. Pp. 212, 155 figs. Lewis, London. ( $f 4$ 10s. $0 d$.).

It is fitting that Choyce has dedicated his book to Harold Ridley, the pioneer with the courage to insert an acrylic lens behind the pupil. It is proper that an authoritative book should at last be written by a surgeon of large experience in this field, its practice still much debated by many and accepted (sometimes with reservations) by a few.

The author has done much to improve Strampelli's anterior chamber lens with a thinner haptic part, the lower edge turned to prevent iris prolapse anterior to it. He has also given much original thought to the use of a coloured haptic for large iris colobomata and aniridia, and for the employment of a stenopaeic slit in the optical part of the lens. Consideration is also given to a concave acrylic anterior chamber lens as the posterior optical part of a Galilean telescopic lens, an aid to low visual acuity due to macular degeneration.

He has given good guidance on the indications and contraindications for this operation. It is clearly evident from his carefully prepared statistics of 500 patients that the results become much better in the last 200 patients so treated.

There are a few faults in the Figures-p. 59, Fig. $(f)$ shows diagrammatically closure of the filtration angle from 3 to 6 o'clock referred to in the text as 3 to 5 o'clock. Fig. 4(a) shows Binkhorst's iris clip lens with the anterior and posterior nylon loops of equal length, but these are shown unequal in Fig. 4. Fig. 55 shows the acrylic lens much too small for the anterior chamber. There are no legends to explain the numerals in Figs 54-65, 75, 78, 81-85, indicating steps in the operations illustrated. In the illustration of Epstein's collar-stud implant it seems unnecessary to inscribe a " $P$ " on the posterior surface for identification when it is obvious.

In the operation of removal of an acrylic anterior chamber lens a cataract knife section is recommended at the limbus. It must be difficult to do this without fouling the edges of the knife.

Criticisms are of minor significance. The use of the first person singular is inevitable and to some extent proper in a monograph. In this book it recurs a little more frequently than is necessary.

The term "case" for "patient" would not have been allowed in a thesis submitted to one of the older Universities some years ago. There are a few misprints-Took has a terminal ' $e$ '.

The book is beautifully illustrated with coloured photographs and paintings and with black and white diagrams. The production, printing, format, and paper are excellent.

The guidance given in this book is of much value to every eye surgeon. It is an admirable addition to many fine ophthalmic monographs. 